\title{
Human responses to carbon dioxide, a follow-up study at recommended exposure limits in non-industrial environments
}

\author{
Zhang, Xiaojing; Wargocki, Pawel; Lian, Zhiwei
}

\section{Published in:}

Building and Environment

Link to article, DOI:

10.1016/j.buildenv.2016.02.014

Publication date:

2016

Document Version

Peer reviewed version

Link back to DTU Orbit

Citation (APA):

Zhang, X., Wargocki, P., \& Lian, Z. (2016). Human responses to carbon dioxide, a follow-up study at recommended exposure limits in non-industrial environments. Building and Environment, 100, 162-171. https://doi.org/10.1016/j.buildenv.2016.02.014

\section{General rights}

Copyright and moral rights for the publications made accessible in the public portal are retained by the authors and/or other copyright owners and it is a condition of accessing publications that users recognise and abide by the legal requirements associated with these rights.

- Users may download and print one copy of any publication from the public portal for the purpose of private study or research.

- You may not further distribute the material or use it for any profit-making activity or commercial gain

- You may freely distribute the URL identifying the publication in the public portal 


\section{Accepted Manuscript}

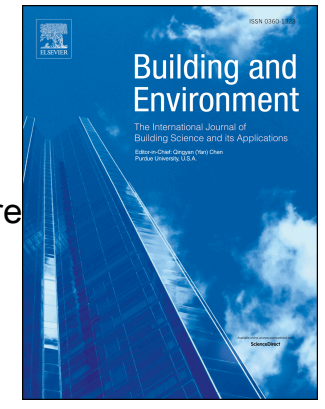

Human Responses to Carbon Dioxide, a Follow-up Study at Recommended Exposure Limits in Non-industrial Environments

Xiaojing Zhang, Pawel Wargocki, Zhiwei Lian

PII: $\quad$ S0360-1323(16)30058-0

DOI: $\quad$ 10.1016/j.buildenv.2016.02.014

Reference: BAE 4400

To appear in: Building and Environment

Received Date: 23 December 2015

Revised Date: 13 February 2016

Accepted Date: 16 February 2016

Please cite this article as: Zhang X, Wargocki P, Lian Z, Human Responses to Carbon Dioxide, a Follow-up Study at Recommended Exposure Limits in Non-industrial Environments, Building and Environment (2016), doi: 10.1016/j.buildenv.2016.02.014.

This is a PDF file of an unedited manuscript that has been accepted for publication. As a service to our customers we are providing this early version of the manuscript. The manuscript will undergo copyediting, typesetting, and review of the resulting proof before it is published in its final form. Please note that during the production process errors may be discovered which could affect the content, and all legal disclaimers that apply to the journal pertain. 


\section{Human Responses to Carbon Dioxide, a Follow-up Study at}

\section{Recommended Exposure Limits in Non-industrial Environments}

Xiaojing Zhang ${ }^{\mathrm{a}, \mathrm{b}}$, Pawel Wargocki ${ }^{\mathrm{b}}$, and Zhiwei Lian ${ }^{\mathrm{a}, *}$

${ }^{\text {a }}$ School of Naval Architecture, Ocean \& Civil Engineering, Shanghai Jiao Tong University, Shanghai, 200240, China.

${ }^{\mathrm{b}}$ International Centre for Indoor Environment and Energy, Technical University of Denmark, Kongens Lyngby, DK-2800, Denmark

Corresponding author: Room 405, Mulan Chu Chao Building, Shanghai Jiao Tong University, 800 Dongchuan Road, Shanghai 200240, PR China. Tel.: +86 (021)34204263. Fax: +86 (021)34204263. E-mail address: zwlian@ sjtu.edu.cn 
Abstract To extend the results of a previous study on the effects of carbon dioxide $\left(\mathrm{CO}_{2}\right)$ and bioeffluents on humans, the new study reported in this paper was carried out. The purpose of this study was to examine, whether exposure to $\mathrm{CO}_{2}$ at 5,000 ppm would cause sensory discomfort, evoke acute health symptoms, reduce the performance of cognitive tasks, or result in changes in physiological responses. The outdoor air supply rate was set high enough in a low-emission stainless-steel climate chamber to create a reference condition with $\mathrm{CO}_{2}$ at 500 ppm when subjects were present, and chemically pure $\mathrm{CO}_{2}$ was added to the supply air to create an exposure condition with $\mathrm{CO}_{2}$ at 5,000 ppm (the measured exposure level was ca. 4,900 ppm). Ten healthy college-age students were exposed twice to each of the two conditions for 2.5 hours in a design balanced for order of presentation. The raised $\mathrm{CO}_{2}$ concentration had no effect on perceived air quality or physiological responses except for endtidal $\mathrm{CO}_{2}\left(\mathrm{ETCO}_{2}\right)$, which increased more (to $5.3 \mathrm{kPa}$ ) than it was in the reference condition (5.1 kPa). Other results indicate additionally that a 2.5-hour exposure to $\mathrm{CO}_{2}$ up to 5,000 ppm did not increase intensity of health symptoms reported by healthy young individuals and their performance of simple or moderately difficult cognitive tests and some tasks resembling office work. These results accord well with the current occupational exposure limit recommendation for $\mathrm{CO}_{2}$ and with many other reports published in the literature.

Key words Carbon dioxide; Perceived air quality; Acute health symptoms; Cognitive performance; Physiological responses

\section{Practical Implications}

The present results provide some support to the currently recommended occupational exposure limit for $\mathrm{CO}_{2}$. They show that a concentration of $\mathrm{CO}_{2}$ up to 5,000 ppm during brief exposures no longer than $2.5 \mathrm{~h}$, will not decrease perceived air quality, increase intensity of self-assessed acute health symptoms or negatively affect the performance of some aspects of 
office work. Thus a mere removal of $\mathrm{CO}_{2}$ is not sufficient to avoid negative effects of exposures indoors; other pollutants need to be removed as well.

\section{Introduction}

Since the 19th Century, the indoor carbon dioxide $\left(\mathrm{CO}_{2}\right)$ concentration has been used as an indicator of air quality in buildings and of the effective outdoor air supply rate in occupied rooms (Pettenkofer, 1858). Many studies have used $\mathrm{CO}_{2}$ as a marker for exposure levels indoors and for ventilation efficiency, and examined the relationship between measured concentrations of $\mathrm{CO}_{2}$ and subjectively assessed acute health symptoms (e.g., Seppänen et al., 1999; Apte et al., 2000; Erdmann et al., 2002), impairment in cognitive performance (e.g., Myhrvold et al., 1996; Myhrvold and Olesen, 1997; Coley et al., 2004; Bakó-Biró et al., 2008; Haverinen-Shaughnessy et al., 2011; Wargocki and Wyon, 2013) and absence rates (e.g., Milton et al., 2000; Mendell et al., 2013). In all of these studies, none of the observed effects were attributed to $\mathrm{CO}_{2} \cdot \mathrm{CO}_{2}$ was simply regarded as a harmless indicator of the likely presence of harmful pollutants.

The source of $\mathrm{CO}_{2}$ in non-industrial indoor environment is human metabolism. Taking the production rate of $\mathrm{CO}_{2}$ by humans and ventilation rate, the measured levels of $\mathrm{CO}_{2}$ indoors very seldom exceed 5,000 ppm, i.e. the current 8-hour occupational exposure limit set by the Occupational Safety and Health Administration (OSHA) (CCOHS, 2005) and the American Conference of Governmental Industrial Hygienists (ACGIH, 2011); the ceiling limit of 30,000 ppm for 10-minute exposure set by ACGIH is only relevant for industrial exposures as it is highly unlikely that it would occur in non-industrial settings. As summarized in the literature survey performed by Zhang et al. (2016a), at levels below 10,000 ppm no toxic effects of $\mathrm{CO}_{2}$ are expected, and even no physiological responses due to $\mathrm{CO}_{2}$ exposures were observed that could plausibly lead to negative health effects. The published studies show that 
measurable effects on the respiratory system (increased respiratory rate, minute ventilation rate or the arterial partial pressure of $\mathrm{CO}_{2}$ ) and changes in the cardiovascular system (increased heart rate and blood pressure) occur at $\mathrm{CO}_{2}$ concentrations higher than $10,000 \mathrm{ppm}$ or even when $\mathrm{CO}_{2}$ concentrations are above 30,000-50,000 ppm (Sechzer et al., 1960; Schaefer et al., 1963; Woods et al., 1988; Maresh et al., 1997; Bailey et al., 2005). No effects of $\mathrm{CO}_{2}$ on the performance of subtraction, logical reasoning or short-term memory were seen either during brief exposures of $20 \mathrm{~min}$ to $\mathrm{CO}_{2}$ levels up to $65,000 \mathrm{ppm}$ (end-tidal $\mathrm{CO}_{2}$ $\left(\mathrm{ETCO}_{2}\right)$ reached $6.7 \mathrm{kPa}$ ) (Sayer et al., 1987). Thus the previous studies show that negative effects of exposure to pure $\mathrm{CO}_{2}$ occur at concentrations that are at least one order of magnitude higher than those that occur in non-industrial indoor environments.

These results are confirmed by recent study by Zhang et al. (2016a,b). They exposed twenty-five subjects to $\mathrm{CO}_{2}$ at 1,000 ppm and 3,000 ppm; $\mathrm{CO}_{2}$ was dosed from gas cylinders into chamber to attain these two levels, while other pollutants were kept at very low level by setting ventilation at a high rate. Compared to the $\mathrm{CO}_{2}$ level at $500 \mathrm{ppm}$, exposure to $\mathrm{CO}_{2}$ levels up to 3,000 ppm did not cause any significant changes in perceived air quality, the intensity of acute health symptoms rated by the subjects themselves or the performance of cognitive tasks resembling office work. $\mathrm{ETCO}_{2}$ level reached $5.4 \mathrm{kPa}$ at $\mathrm{CO}_{2}$ of 3,000 ppm while it was $5.1 \mathrm{kPa}$ during exposure to $\mathrm{CO}_{2}$ at $500 \mathrm{ppm}$. The performance of a cue-utilization test tended to decrease during exposure to $\mathrm{CO}_{2}$ at 3,000 ppm. No changes in stress/arousal indicators and other physiological responses were found.

Contrary to the studies mentioned above three recent independent studies showed that exposure to elevated $\mathrm{CO}_{2}$ at levels below 3,000 ppm can negatively affect the performance of proof-reading (Kajtár and Herczeg, 2012) and influence a complex test of decision-making ability (Satish et al., 2012; Allen et al., 2015). In these three studies, $\mathrm{CO}_{2}$ was dosed from gas cylinders while ventilation rate was sufficiently high to keep other pollutants at low levels. 
The study by Kajtár and Herczeg (2012) observed some physiological effects of exposure to pure $\mathrm{CO}_{2}$ at 3,000 ppm, including increased diastolic blood pressure and decreased midfrequency components of heart rate variability, which may suggest an elevated stress level; no other health effects were observed. Satish et al. (2012) and Allen et al. (2015) did not report any results of physiological responses or results of measurements of health effects.

The present study was carried out to further examine the effects of exposure to pure $\mathrm{CO}_{2}$ and to investigate the possible reasons for the discrepancy between the findings by Zhang et al. (2016a,b) and the above studies by Kajtár and Herczeg (2012), Satish et al. (2012) and Allen et al. (2015). The hypothesis was that no measured outcomes would be changed by increasing $\mathrm{CO}_{2}$ to $5,000 \mathrm{ppm}$, i.e. to the current 8-hour occupational exposure limit and the level higher than that examined in the previous studies mentioned above (Kajtár and Herczeg, 2012; Satish et al., 2012; Allen et al., 2015).

\section{Methods}

\subsection{Approach}

The experimental approach was similar to that used in a previous experiment by Zhang et al. (2016a,b). Ten subjects in two groups of five were exposed in a stainless climate chamber for 153 minutes to two conditions: a reference exposure condition when $\mathrm{CO}_{2}$ generated by subjects occupying the chamber was kept at $500 \mathrm{ppm}$, and an exposure condition when $\mathrm{CO}_{2}$ was elevated to 5,000 ppm by dosing it from the gas cylinders. The order of presentation of conditions was balanced according to the Latin-square design. The subjects were exposed twice to each condition, thus they were exposed in the chamber for four times: They were first exposed to the pair of conditions $\left(\mathrm{CO}_{2}\right.$ at 500 and 1,000 ppm) and then to the same pair of conditions in the reversed order. The subjects remained blind to exposure conditions. During each exposure, they rated air quality and thermal comfort, assessed the intensity of their acute 
health symptoms, indicated the level of effort they had exerted and performed a number of cognitive performance tasks. The physiological responses of the subjects were monitored to examine whether there were any effects on respiratory or cardiovascular systems. Saliva samples were collected for later analysis of stress biomarkers.

\subsection{Facilities}

The experiment was carried out in the climate chamber described in detail by Albrechtsen (1988) and Zhang et al. (2016b). The chamber is made of stainless steel. It has a floor area of $3.6 \times 2.5 \mathrm{~m}$ and a volume of $30 \mathrm{~m}^{3}$ including recirculation ducts. The ventilation is achieved by using a piston-type air distribution through a perforated floor with a sub-floor plenum. A grid is placed above the perforated plate to allow walking. The size and distribution of the holes in the perforated plate is designed to obtain uniform airflow over the grid at a very low air velocity. Consequently, there are no complaints of uncomfortable air movement (draft) even when the chamber is operated at the highest possible air change rate up to $60 \mathrm{~h}^{-1}$. The air in the chamber is well mixed due to air distribution principle and recirculation. New G3/F7 particle filters were installed in the supply ducts immediately prior to the present experiment. No other filters or air cleaners were used. The chamber was thoroughly cleaned prior to the experiments and 'baked' for one week at a temperature of $40^{\circ} \mathrm{C}$ to reduce any residual pollution on the inner surfaces of the chamber and its ducting. No chemical measurements were performed prior to the experiment to examine whether the background pollution level was in fact low, but many previous experiments performed in the same chamber have documented that the chamber is indeed low-emitting (e.g., Fang et al., 1998a,b; Kjærgaard et al., 1999; Pejtersen et al., 2001; Zhang et al., 2016b). The sensory assessments of air quality made by the subjects in the present experiment (see the Results section and Fig. 2) confirm that the level of perceived air quality was high in the chamber and thus that the levels of any 
residual pollutants in the chamber volume were low. There were six workstations in the chamber for the 5 subjects and an experimenter, each workstation consisting of a table, a chair, a laptop PC and a desk lamp.

\subsection{Subjects}

Ten healthy college-age subjects ( 5 males, 5 females) were recruited to take part in the experiments and all of them completed all 4 scheduled exposures. All subjects were students with a mean \pm SD age of $25 \pm 2$ years old, mean \pm SD height of $176 \pm 8 \mathrm{~cm}$ and mean \pm SD weight of $70 \pm 9 \mathrm{~kg}$. They were all non-smokers. All subjects received a 1-hour session of training prior to the experiments. During this session they were instructed on how to fill out the questionnaires, they practiced the cognitive tasks used for measuring performance, and the physiological measurements were made so they could get familiar with all procedures. The subjects were asked to adjust their clothing to remain thermally neutral during the practice session (the average thermal insulation of their clothing after this session was about 0.37 clo). They were then requested to wear garments with similar insulation during the actual experiments. The subjects were instructed to avoid drinking alcohol or eating spicy food on the day prior to and on the day of exposure. They were also asked not to use strong perfume or perfumed hygienic products on the exposure days. The subjects were paid at a fixed rate for taking part in the experiments.

\subsection{Experimental Conditions}

Two exposure conditions were established in the chamber: a reference exposure condition with $\mathrm{CO}_{2}$ at $500 \mathrm{ppm}$ (referred to as $\mathrm{B} 500$ ) and an exposure condition with elevated $\mathrm{CO}_{2}$ at 5,000 ppm (referred to as P5000). 
In the reference condition (B500), the ventilation rate was set at $720 \mathrm{~m}^{3} / \mathrm{h}$ (corresponding to $\left.24 \mathrm{~h}^{-1}\right)$. This was high enough to reduce the $\mathrm{CO}_{2}$ concentration generated by 5 subjects and the experimenter who remained in the chamber during exposures to $500 \mathrm{ppm}$. The concentration of human bioeffluents emitted by the subjects and the experimenter will also have been reduced to a correspondingly low level. In the high exposure condition of 5,000 ppm (P5000), the ventilation rate was the same as in the reference condition, in order to keep the concentration of background emissions, human bioeffluents and metabolically-generated $\mathrm{CO}_{2}$ as low as in $\mathrm{B} 500$. In this condition, $\mathrm{CO}_{2}$ (99.99\% in quality) was added to the supply air at a constant rate of $54 \mathrm{~L} / \mathrm{min}$ to maintain its concentration in the chamber at a level close to 5,000 ppm. Real-time measurements of $\mathrm{CO}_{2}$ concentration in the climate chamber were made during exposures to ensure that the intended concentrations were achieved and to ensure that $\mathrm{CO}_{2}$ levels did not exceed 5,000 ppm.

In both exposure conditions, temperature, relative humidity, noise level and lighting level were kept constant at $26^{\circ} \mathrm{C}, 35 \%, 48 \mathrm{~dB}(\mathrm{~A})$ and 380 lux. Two-degrees higher temperature than in the study by Zhang et al. (2016a,b) was selected because the present experiment was performed in summer (mid August 2014), while the previous study was carried out in late winter and early spring (from February to April). The subjects reported to be approximately thermally neutral during practice session at $26^{\circ} \mathrm{C}$ and also in all four exposures (see the Results section). Another reason for selecting this temperature was to match the thermal condition with an experiment that examined the effects of elevated temperature $\left(35^{\circ} \mathrm{C}\right)$ and the combined effects of elevated temperature and $\mathrm{CO}_{2}$ (Liu and Wargocki, 2015; Liu et al., 2016).

2.5 Measurements 
A measurement station was placed in the chamber at the head height of a seated person. It consisted of a calibrated CARBOCAP ${ }^{\circledR} \mathrm{CO}_{2}$ monitor (GMW22, Vaisala, Finland) with a measuring range of $0-5,000 \mathrm{ppm}$ and an accuracy of $\pm 2 \%$ of range $+2 \%$ of reading, and a response time of $1 \mathrm{~min}$, a sensor for temperature (measurement range $0-50^{\circ} \mathrm{C}$, accuracy $\pm 0.35^{\circ} \mathrm{C}$ ) and relative humidity (measurement range $10-90 \%$, accuracy $\pm 2.5 \%$ ), and a HOBO U12-013 data logger (Onset Computer Corp., USA) connected to the sensors to record the data. $\mathrm{CO}_{2}$ concentration, air temperature and humidity were monitored continuously. Ozone concentration was measured continuously at the centre of the chamber using an ozone monitor Model 205 by 2B Technologies Inc. (measurement range $1 \mathrm{ppb}$ to $250 \mathrm{ppm}$, accuracy $\pm 2 \%$ of reading). Lighting intensity and sound level were measured when no occupants were present in the chamber. The lighting intensity was measured with a lux meter Testo 540 by Testo AG (measurement range 0-99,999 lux, accuracy $\pm 3 \%$ ) and the sound level was measured with a digital sound level meter by EXTECH (measurement range 35-130 dB(A), accuracy $\pm 1.5 \mathrm{~dB}(\mathrm{~A}))$. It must be remarked that the accuracy of instruments presented above is based on the specifications provided by the manufacturers.

Subjective measurements were carried out using the same questionnaires as were used in the previous study by Zhang et al. (2016b). They included questions regarding perception of indoor environment, including the acceptability of the air quality, odour intensity, air freshness, thermal sensation and acceptability of thermal environment, air dryness, brightness and noise level. The intensity of each of the following acute health symptoms was rated by the subjects: nose dryness, throat dryness, skin dryness, eye dryness, eyeache, headache, difficulty in thinking clearly, difficulty in concentration, fatigue, dizziness, depression and sleepiness. Ratings of self-estimated performance were collected too. The subjective assessments described above were obtained repeatedly during each exposure, as shown in Fig. 1. 
During the exposures, the subjects performed text typing and addition to examine the effects of increased $\mathrm{CO}_{2}$ on the component skills required to perform office work (Fig. 1). Each task took 30 minutes to complete. In the text typing task, subjects retyped a printed English text onto the PC using Microsoft Word; the number of characters typed per minute and the error rate were calculated as the measures of performance. The error rate was estimated using the Levenshtein distance, which is a measure of the difference between a source string and a target string; a higher Levenshtein distance indicates more differences between two strings, i.e. that more errors were made (Levenshtein, 1966). In the addition task, subjects added five two-digit numbers that were printed in a vertical column; the number of units completed per minute and the percentage error rate were calculated. The subjects also performed a cue-utilization test known as the Tsai-Partington test (Partington, 1949; Partington and Leiter, 1949), in which they drew a line as quickly and accurately as possible connecting numbers in the ascending order. Thirty numbers were selected randomly between 1-99 and were scattered randomly on a page. The time allocated to perform the test was $40 \mathrm{~s}$, which was too short for the subjects to connect all of the numbers. The total number of correct links made during the available time was counted as the measure of performance.

Several physiological measurements were made. They included continuous measurement of heart rate using a Suunto belt (SS014543000, Suunto Oy), measurements of blood pressure immediately prior to and after the exposure using a Beurer BM 35 monitor, measurements of respiration rate overlapping the periods of text typing, using an apparatus developed by the experimental team consisting of a thermistor attached to a headset (Zhang et al., 2016b), and three repeated measurements of $\mathrm{ETCO}_{2}$ and $\mathrm{SPO}_{2}$ immediately prior to each exposure and each hour during the exposure, using a Lifesense Monitor by MedAir AB. The measurable range of $\mathrm{ETCO}_{2}$ was $0-9.9 \mathrm{kPa}$ and the accuracy was $\pm 0.2 \mathrm{kPa}+6 \%$ of reading; the measurable range of $\mathrm{SPO}_{2}$ was $0-100 \%$ and the accuracy was $\pm 2 \%$ as provided by the 
manufacturer. In addition, saliva samples were collected before and after the exposure for later analysis of the changes in two stress biomarkers: $\alpha$-amylase and cortisol. The samples were collected by asking subjects to drool into a container. Immediately after collection, the saliva samples were centrifuged and stored in a freezer (storage temperature $-20^{\circ} \mathrm{C}$ ) until they were sent for analysis performed by a certified laboratory. Amylase assay was performed with Integra 400 plus (Roche Diagnostics Ltd.). The detection limit was $3 \mathrm{U} / \mathrm{L}(0.003 \mathrm{U} / \mathrm{ml})$ and the analytical error of measurement was 5.7\%. Cortisol assay was performed with Cobas 6000/e601 (Roche Diagnostics Ltd.). The detection limit was $0.018 \mathrm{ug} / \mathrm{dl}(0.4968 \mathrm{nmol} / \mathrm{L})$, and the analytical error of the measurement was $11.7 \%$. The analytical accuracy of saliva bioassays was provided by the commercial laboratory that performed analyses.

\subsection{Experimental Procedure}

The experiment was conducted in two successive weeks in the middle of August 2014, each week from Monday to Thursday. The subjects were randomly assigned to 2 groups of 5 subjects; one group participated in the experiments on Mondays and Wednesdays, while the other took part on Tuesdays and Thursdays always on the same time of the day.

Each day, the experiment started at 14:00 and ended by 17:00 (Fig. 1). Immediately upon arrival, the subjects put on the Suunto belt, blood pressure and $\mathrm{ETCO}_{2} / \mathrm{SPO}_{2}$ were measured, and saliva samples were obtained. Once these physiological measurements were completed, the subjects entered the chamber. Immediately upon entering the chamber, they assessed air quality and odour intensity. They then sat down at their respective workstations and performed assessments and tasks according to the schedule shown in Fig. 1.

After the 153-minute exposure the subjects left the chamber. Blood pressure was measured and saliva samples were obtained again. The subjects then re-entered the chamber and immediately upon entering assessed again the air quality and odour intensity. 
The study conformed with the Ethics Review Board approval (KA04741).

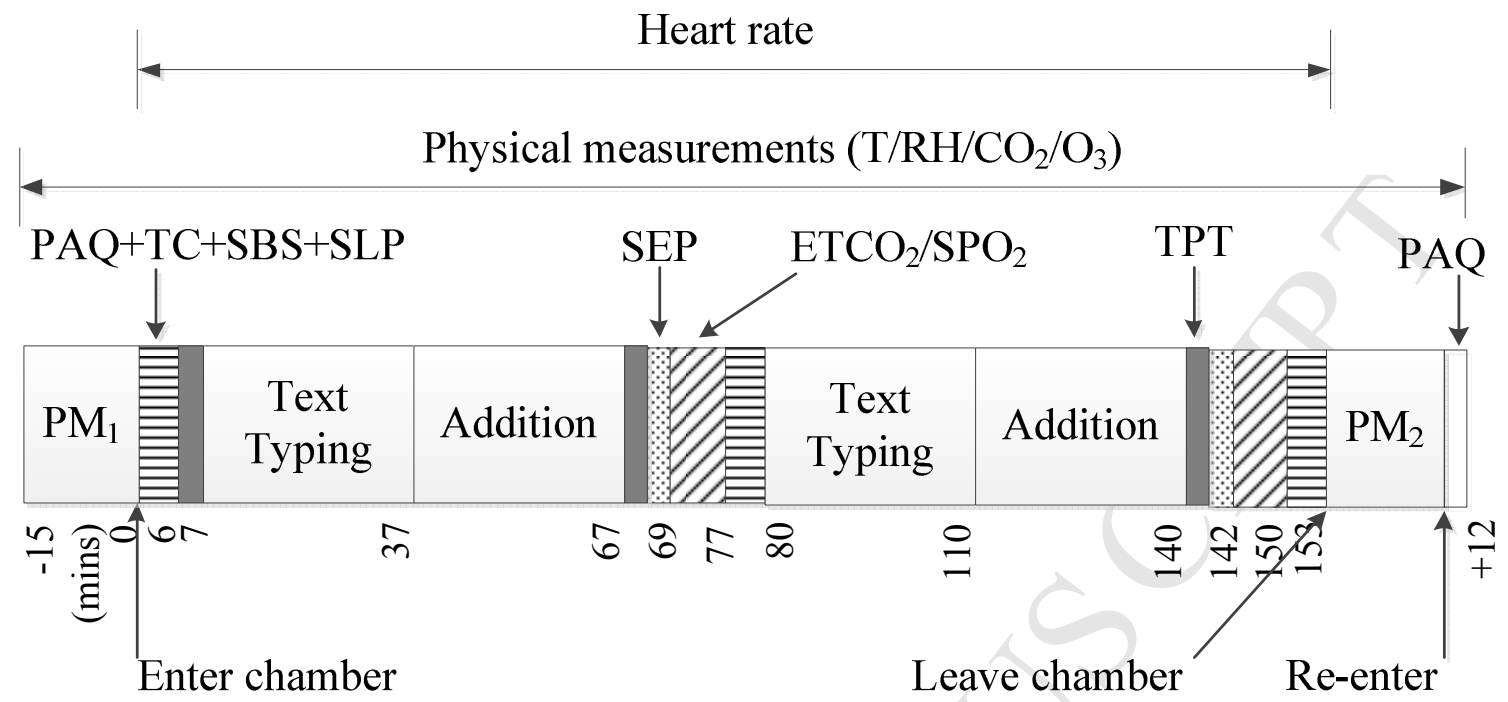

Fig. 1 Experimental procedure, where PAQ/TC/SBS/SLP stands for assessments of perceived air quality, thermal conditions, acute health symptoms and sleepiness; SEP stands for selfestimated performance; TPT stands for Tsai-Partington test; PM stands for physiological measurements, $\mathrm{PM}_{1}$ includes measurements of $\mathrm{ETCO}_{2} / \mathrm{SPO}_{2}$, blood pressure and saliva sampling, while $\mathrm{PM}_{2}$ includes only measurement of blood pressure and saliva sampling

\subsection{Statistical Analysis}

Measures of central tendency and variance were obtained for all parameters measured and rated by the subjects separately for each week after all data had been checked for gross errors. All outcomes were analysed using a general linear analysis of variance model with repeated measures. Exposure conditions (c) and the time at which different assessments were made during the day $(t)$ were included as within-subject factors; condition $\times$ time interaction $(c t)$ was automatically included in the model as a within-subject factor. It was independently examined whether week-to-week responses were consistent. Because they were not significantly different from each other, repetition was not included in the model as a factor. The analysis 
was made with the SPSS 19.0 program. This program was also used to perform post-hoc analyses using a paired t-test, whose purpose was to compare differences between conditions at the same time moments or between time moments within the same condition. The significance level was set to 0.05 (2-tail).

Although only ten subjects participated in the present experiment, the repeated measures design with repetition secures that the statistical power of the present study is 0.92 as calculated from post-hoc power analysis using software G*power 3.0 (Faul et al., 2007), assuming a large effect size at 0.4 based on the prior similar experiments with human subjects (Lan and Lian, 2010; Lan et al., 2011). The statistical power of the present study is higher than of the preceding study by Zhang et al. (2016a,b). Zhang et al. examined the effects of elevated $\mathrm{CO}_{2}$ exposures, and 25 subjects participated. Repeated measures design without repetition was used and the statistical power was 0.85 . The statistical power of both studies was higher than 0.8 , which is the generally acceptable level.

\section{Results}

Table 1 shows that the conditions measured in the chamber were close to the intended values.

The $\mathrm{CO}_{2}$ level in the high $\mathrm{CO}_{2}$ condition (P5000) was slightly lower than planned (by about $100 \mathrm{ppm}$ ) to make sure that it did not exceed the occupational exposure limit. Table 1 shows that other parameters did not differ between the two exposure conditions.

Table 1 Measured conditions during exposures in the chamber (mean \pm SD)

\begin{tabular}{ccccccc}
\hline Condition & $\begin{array}{c}\mathrm{CO}_{2} \\
(\mathrm{ppm})\end{array}$ & $\begin{array}{c}\text { Temperature } \\
\left({ }^{\circ} \mathrm{C}\right)\end{array}$ & $\begin{array}{c}\text { Humidity } \\
(\%)\end{array}$ & $\begin{array}{c}\text { Indoor } \mathrm{O}_{3} \\
(\mathrm{ppb})\end{array}$ & $\begin{array}{c}\text { Lighting } \\
(\mathrm{Lux})\end{array}$ & $\begin{array}{c}\text { Noise } \\
(\mathrm{dB}(\mathrm{A}))\end{array}$ \\
\hline B500 & $409 \pm 21$ & $26.1 \pm 0.1$ & $35 \pm 2$ & $31 \pm 8$ & $378 \pm 73$ & $48 \pm 0.5$ \\
P5000 & $4913 \pm 146$ & $26.0 \pm 0.2$ & $35 \pm 2$ & $34 \pm 3$ & & \\
\hline
\end{tabular}


There was no significant difference in the assessments of acceptability of air quality between reference exposure (B500) and the high $\mathrm{CO}_{2}$ exposure (P5000) both upon entering the chamber prior to exposure, during exposures in the chamber, and upon re-entering the chamber after the exposures were completed (Fig. 2). The estimated percentage of subjects dissatisfied with air quality, calculated from the ratings of acceptability of air quality, was about $10 \%$ (Wargocki, 2004). This indicated that the background pollution level in the chamber was indeed low, as expected, and that the elevated $\mathrm{CO}_{2}$ level did not change sensory responses of subjects. This was further confirmed by the assessments of odour intensity and air freshness (Fig. 2): subjects assessed the intensity of the odour in the chamber close to slight and the air was perceived as neither stuffy nor fresh independently of the exposure conditions.

Subjects reported that they felt slightly warmer than neutral during the exposures, but the thermal sensation reported by the subjects did not differ between conditions (Fig.2). Subjects reported that the acceptability of the thermal conditions was quite high; using these assessments it was estimated that fewer than $12 \%$ of the subjects were dissatisfied with the thermal conditions. The ratings of perceived brightness, air dryness and noise level did not differ between exposure conditions (data not shown). 

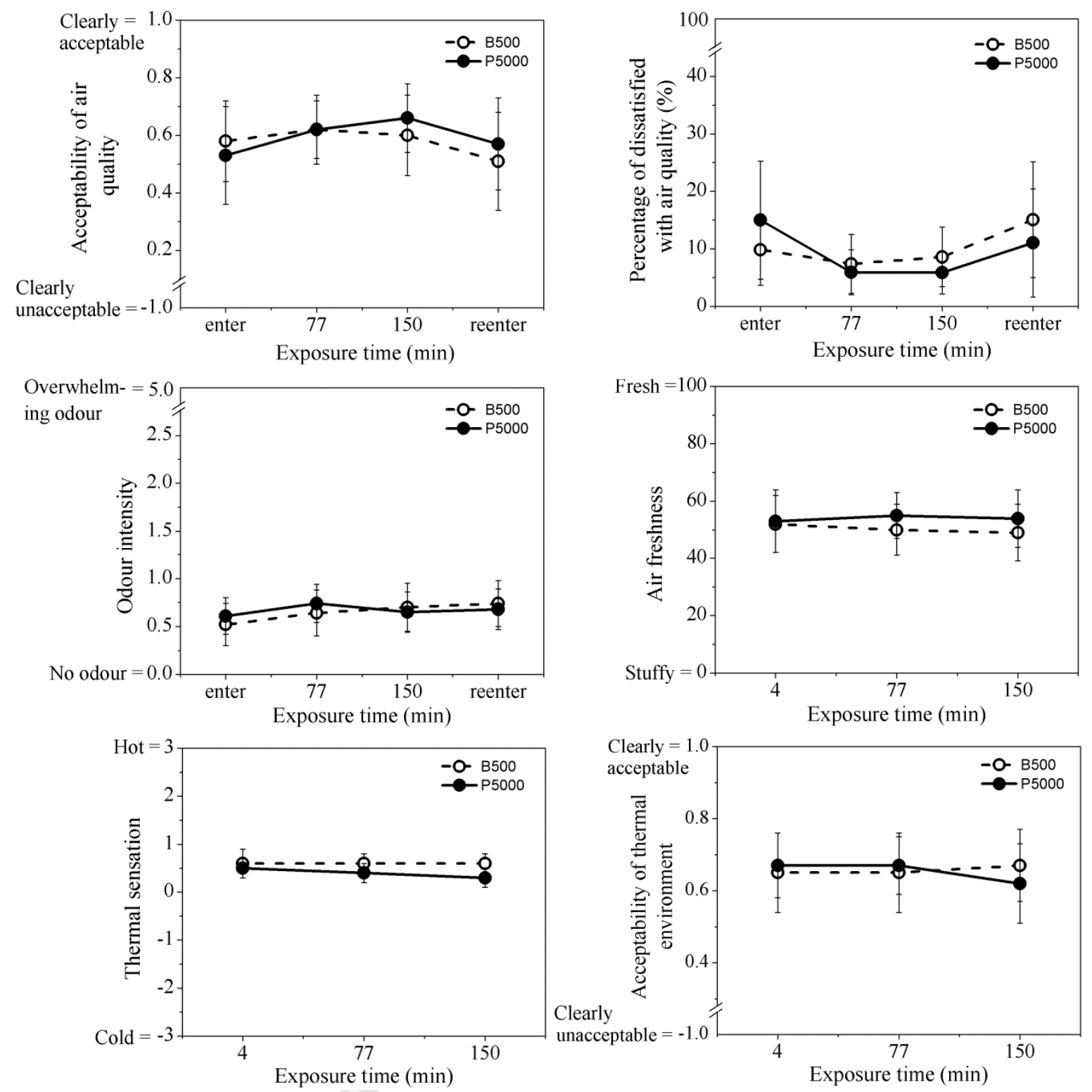

Fig. 2 Subjective perceptions of air quality and thermal condition in the chamber; the bars show the $95 \%$ confidence interval $(95 \% \mathrm{CI})$

Fig. 3 shows the ratings of the intensity of the acute health symptoms reported by the subjects; only symptoms that either differed between the exposure conditions or changed in the course of exposures are shown. The only occasion when the intensity of any symptom differed significantly between conditions was for the nose dryness. It was systematically less intense at P5000 than at B500; the difference was however small and it was statistically significant only at the beginning of exposure. Subjects reported that they felt worse, were 
more tired and sleepy, and it was more difficult to think clearly and concentrate the longer they stayed in the chamber. These temporal changes were statistically significant but they did not differ between the exposure conditions (Fig. 3). There was no significant change in the intensity of any other symptoms (data not shown).
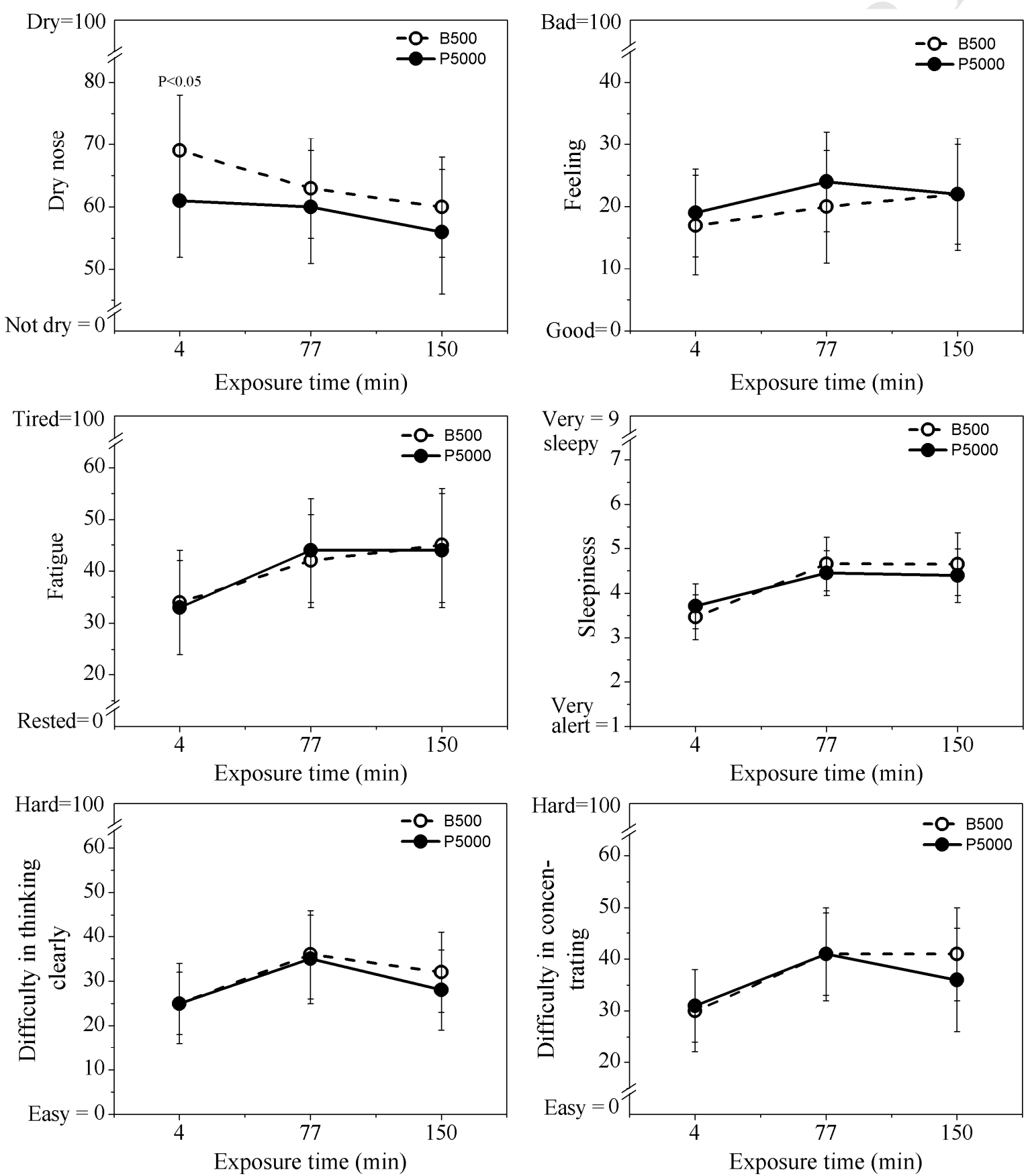

Fig. 3 Intensity of acute health symptoms that differed significantly between conditions (only 
nose dryness) or changed significantly over the exposure time (all symptoms presented); the bars show the $95 \% \mathrm{CI}$

There were no significant differences in self-estimated performance between the two exposure conditions.

Table 2 shows that there were no significant differences between the two exposure conditions in the performance of Tsai-Partington test or cognitive tasks resembling office work.

Table 2 Performance of Tsai-Partington test, text typing and addition tasks (Mean $\pm 95 \% \mathrm{CI}$ )

\begin{tabular}{llccc}
\hline \multirow{2}{*}{ Task } & \multicolumn{1}{c}{ Index } & \multicolumn{2}{c}{ Condition } & \multirow{2}{*}{$\begin{array}{c}p \text {-value for difference } \\
\text { between conditions }\end{array}$} \\
\cline { 2 - 4 } & \multicolumn{1}{c}{ B500 } & P5000 & 0.175 \\
Tsai-Partington & Number of correct connections & $10.9 \pm 0.8$ & $10.3 \pm 0.7$ & 0.122 \\
Text typing & Characters typed per minute & $165.7 \pm 7.8$ & $174.1 \pm 7.8$ & 0.198 \\
& Error rate (\%) & $1.3 \pm 0.2$ & $1.5 \pm 0.3$ & 0.768 \\
\multirow{2}{*}{ Addition } & Units completed per minute & $3.8 \pm 0.4$ & $3.8 \pm 0.4$ & 0.830 \\
& Error rate (\%) & $6.1 \pm 1.4$ & $6.3 \pm 1.9$ & \\
\hline
\end{tabular}

Fig. 4 (left) shows that $\mathrm{ETCO}_{2}$ increased during both exposure conditions compared with the pre-exposure level. The levels of $\mathrm{ETCO}_{2}$ were systematically higher in P5000 compared with $\mathrm{B} 500$, although the differences were small. $\mathrm{ETCO}_{2}$ levels during the exposures (the last two measurements shown in Fig. 4 left) were averaged and compared: The average level of $\mathrm{ETCO}_{2}$ for P5000 was significantly higher than for B500 (P<0.05) (Fig. 4 right). 

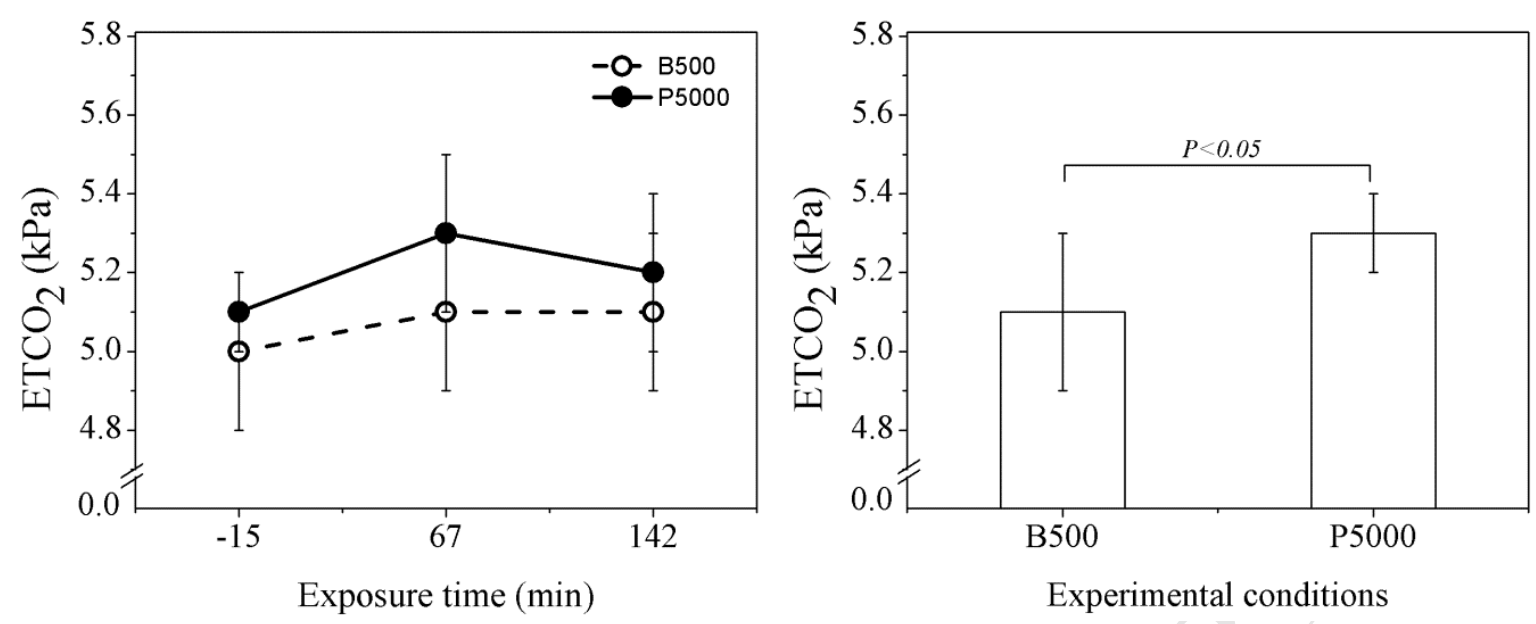

Fig. 4 Change of $\mathrm{ETCO}_{2}$ along the course of exposure (left) and average of $\mathrm{ETCO}_{2}$ during the exposure in each condition (right); the first measurement of $\mathrm{ETCO}_{2}$ was implemented 15 minutes prior to entering the chamber; the bars show 95\% CI

The exposure to 5,000 ppm did not cause any measurable changes in respiration rate.

Due to instrument failure the results of heart rate measurements were available only for 5 subjects. The available data show that there were no systematic differences in heart rate between the two exposure conditions. Heart rate decreased slightly over the course of exposure, but this decline was independent of exposure conditions.

No change in blood pressure was observed after 2.5-hour exposure compared to the preexposure levels in either exposure conditions.

$\mathrm{SPO}_{2}$ increased slightly over the course of the exposure independently of conditions but no significant differences between exposure conditions were observed.

Table 3 shows the concentrations of salivary $\alpha$-amylase and cortisol prior to and after each exposure. The level of salivary $\alpha$-amylase was higher prior to exposure to $\mathrm{CO}_{2}$ at $5,000 \mathrm{ppm}$ (P5000) compared with B500. It decreased after 2.5-hour exposure independently of the exposure conditions. The decline was statistically significant only when the subjects were exposed to B500. Consequently, the $\alpha$-amylase level after exposure to P5000 was higher than 
after exposure to B500. No difference in cortisol levels was observed between the two exposure conditions. The cortisol levels decreased after 2.5-hour exposure independently of conditions and the decrease was again statistically significant only at B500.

Table 3 Concentrations of $\alpha$-amylase and cortisol in Saliva (Mean $\pm 95 \% \mathrm{CI}$ )

\begin{tabular}{ccccccccc}
\hline \multirow{2}{*}{ Condition } & \multicolumn{3}{c}{$\alpha$-amylase (U/ml) } & & \multicolumn{3}{c}{ Cortisol (nmol/l) } \\
\cline { 2 - 4 } \cline { 7 - 9 } \cline { 7 - 9 } & Before & After & After-Before & & Before & After & After-Before \\
\hline B500 & $136.8 \pm 44.7$ & $98.3 \pm 25.2$ & $-19.1 \pm 20.9^{*}$ & & $14.6 \pm 1.5$ & $12.3 \pm 1.2$ & $-1.0 \pm 1.1^{*}$ \\
P5000 & $142.1 \pm 45.5$ & $131.5 \pm 49.3$ & $-5.1 \pm 22.4$ & & $14.5 \pm 2.6$ & $13.2 \pm 1.7$ & $-0.5 \pm 1.7$ \\
\hline
\end{tabular}

*denotes that the difference between the levels prior to and after the exposure was statistically significant $(\mathrm{P}<0.05)$.

\section{Discussion}

In the previous study, Zhang et al. (2016a,b) exposed subjects for 4.5 hours to elevated $\mathrm{CO}_{2}$ at 1,000 ppm and 3,000 ppm; the elevated $\mathrm{CO}_{2}$ levels were attained with similar approach as used in the present study, i.e. by adding it from cylinders and keeping all other pollutants at low levels by ensuring a high ventilation rate. No changes in responses of the subjects were seen at either of the two exposure conditions as regards the perceived air quality, thermal comfort, acute building-related health symptoms or cognitive performance. The present study confirms these findings and extends the previous findings and conclusions to the $\mathrm{CO}_{2}$ level of $5,000 \mathrm{ppm}$, although for exposures lasting only 2.5 hours.

$\mathrm{ETCO}_{2}$ was the only physiological response among many other physiological responses measured in the present experiment that differed between the exposure conditions. Exposure to $\mathrm{CO}_{2}$ at $5,000 \mathrm{ppm}$ for 2.5 hours resulted in $\mathrm{ETCO}_{2}$ of $5.3 \mathrm{kPa}$, while $\mathrm{ETCO}_{2}$ was $5.1 \mathrm{kPa}$ in the reference exposure condition when $\mathrm{CO}_{2}$ was 500 ppm (Fig. 4). This is consistent with the results obtained in the previous study by Zhang et al. (2016a), where the similar trend was observed during exposure to pure $\mathrm{CO}_{2}$ at 3,000 ppm (the levels of $\mathrm{ETCO}_{2}$ was then $5.4 \mathrm{kPa}$ ). Other experiments have shown that exposure to considerably higher $\mathrm{CO}_{2}$ concentrations of 
30,000 ppm to 65,000 ppm can result in notably increased $\mathrm{ETCO}_{2}$. These concentrations can increase $\mathrm{ETCO}_{2}$ to as high as $6.0 \mathrm{kPa}$ to $7.9 \mathrm{kPa}$ (e.g., Consolazio et al., 1947). $\mathrm{ETCO}_{2}$ is increased because of changes in respiration rate and tidal volume (Guillerm and Radziszewski, 1978; Schaefer, 1979); no changes in respiration rate were observed in the present experiment. It is therefore likely that the tidal volume caused that $\mathrm{ETCO}_{2}$ increased. However, the tidal volume was not measured in the present experiment, so it is not possible to verify this postulation. Zhang et al. (2016a,b) also postulated that tidal volume increased when subjects were exposed to $\mathrm{CO}_{2}$ at 3,000 ppm.

Although $\mathrm{ETCO}_{2}$ increased somewhat in the present experiments, this change did not cause any negative effects. Increased $\mathrm{ETCO}_{2}$ can cause changes in breathing pattern, as discussed above, but can also affect cognitive performance. For the latter to occur, Sayers et al. (1987) suggest that $\mathrm{ETCO}_{2}$ must rise above $6.8 \mathrm{kPa}$ (51 Torr), which is much higher than the $5.3 \mathrm{kPa}$ measured in the present experiment (Fig. 4). The study by Sayers et al. (1987) did not observe any habituation during $80 \mathrm{~min}$ exposure to $\mathrm{CO}_{2}$ level of $65,000 \mathrm{ppm}$, during which period $\mathrm{ETCO}_{2}$ increased remarkably; they also noticed that there was a non-significant tendency for $\mathrm{ETCO}_{2}$ to marginally decline towards the end of the exposure. The reason could be that long periods with increased $\mathrm{ETCO}_{2}$ can result in some physiological adaptation. Schaefer (1979) showed that in such case, excess $\mathrm{CO}_{2}$ would be removed through accumulation in the bones, and when a critical level is reached, through the kidneys. It should be noted that Schaefer made these observations during exposures to ambient levels of $\mathrm{CO}_{2}$ in the range of 7,000 $10,000 \mathrm{ppm}$, i.e. at the levels that were higher than the levels normally measured indoors as well as higher than the levels studied in the present experiment.

Zhang et al. (2015a) observed that heart rate decreased less when $\mathrm{CO}_{2}$ was 3,000 ppm compared with the reference condition of $500 \mathrm{ppm}$, but no such difference in heart rate was observed in the present experiment. A possible reason could be that heart rate data were only 
available for 5 subjects and that the exposure time was only 2.5 hours. In the previous study by Zhang et al. (2016a), heart rate data were available for 25 subjects and the exposure time was 4.5 hours.

No other physiological responses to exposure to pure $\mathrm{CO}_{2}$ at 5,000 ppm were observed in the present experiment. This agrees well with previous experiments by Zhang et al. (2016a,b) and others, e.g. Law et al. (2010), showing no physiological reactions during exposure to pure $\mathrm{CO}_{2}$ at any level below $10,000 \mathrm{ppm}$. That physiological responses at two exposure conditions did not differ either prior to experiments suggests additionally that prior exposures before arriving to the experiments did not affect the present results.

That cognitive performance was not affected by exposure to $\mathrm{CO}_{2}$ at $5,000 \mathrm{ppm}$ is in agreement with some of the research published previously, which actually did not observe negative effects of $\mathrm{CO}_{2}$ even when it was one order of magnitude higher than in present experiment. Case and Haldane (1941) did not see any negative effects on the performance of skill and arithmetic tests after a few minutes of exposure to $\mathrm{CO}_{2}$ as high as 60,000-70,000 ppm. Sayers et al. (1987) did not see effects on the Baddeley test of logical reasoning during exposures to $\mathrm{CO}_{2}$ at $65,000 \mathrm{ppm}$ that were up to $80 \mathrm{~min}$ long. They also reported that other studies did not observe any effects on reaction time (Sheehy et al., 1982; Henning et al., 1985), short term memory (Sheehy et al., 1982) or arithmetic tests (Case and Haldane, 1941; Consolazio et al., 1947) during exposures to $\mathrm{CO}_{2}$ at levels up to $60,000 \mathrm{ppm}$. The present results are different however from the studies by Kajtár and Herczeg (2012), Satish et al. (2012) and Allen et al. (2015) who showed the negative effects of $\mathrm{CO}_{2}$ on cognitive performance. Kajtár and Herczeg (2012) observed a decrease in the performance of a proofreading task during 3-hour exposure to $\mathrm{CO}_{2}$ at 3,000 ppm, but the description of their experiment was inadequate in some respects and the effect was observed only on one occasion during two series of experiments. The studies by Satish et al. (2012) and Allen et al. 
(2015) were obtained in experiments with a very strong design, controlling well for possible confounding and disturbing factors. Their results were very systematic and consistent. They showed that exposure to $\mathrm{CO}_{2}$ reduced significantly the performance of a complex test of decision-making at levels as low as 1,000 ppm during up to 8-hour exposure. They used a battery of tests known as the Strategic Management Simulation (SMS) (Streufert et al., 1988; Breuer et al., 2003; Satish et al., 2004). This test is very different from the tasks used in the present study as well as other studies mentioned above. It examines higher-order cognitive skills by exposing participants to unfamiliar situations based on real-world equivalent challenges in complex decision-making. The SMS test requires using many skills and abilities (i.e. it is multi-tasking) and consequently it needs a high cue-utilization capacity, i.e. a low arousal/stress level. Considering present results it may be postulated that simple or familiar cognitive tasks may not be affected by elevated $\mathrm{CO}_{2}$ levels. Considering the work by Satish et al. (2012) and Allen et al. (2015), it may additionally be postulated that $\mathrm{CO}_{2}$ is only critical for certain tasks, which are not typical or widely exercised by work force in offices.

Since no toxic effects of $\mathrm{CO}_{2}$ at the levels used by Satish et al. (2012) or Allen et al. (2015) would be expected based on the published research (e.g. Schaefer, 1979; Law et al., 2010; Zhang et al., 2016a), it seems possible that poor performance of the SMS test could be due to other reasons. It may be postulated that reduced performance occurred because of the elevated stress/arousal level of individuals taking the test. Because SMS is complex, difficult and unfamiliar, it may create stressful situation resulting in elevated arousal, as postulated by Yerkes-Dodson (1908). This may result in less than optimal performance even at low $\mathrm{CO}_{2}$ levels close to background levels. According to the Yerkes-Dodson Law, further increase in arousal would have negative effects on the performance of such a test. This would suggest that elevated $\mathrm{CO}_{2}$ levels in the studies by Satish et al. (2012) and Allen et al. (2015) increased arousal, and this was the main reason causing the poor performance of SMS. In the present 
study and the study by Zhang et al. (2016a,b), there was a weak indication that $\mathrm{CO}_{2}$ might increase arousal/stress levels slightly: There was a non-significant tendency for performance of Tsai-Partington test, which is a much more direct test of cue-utilization than SMS, to be reduced during exposures to high $\mathrm{CO}_{2}$ levels, even though there were no other indications of elevated stress, i.e. other stress indicators, including blood pressure and salivary biomarkers, were not affected. Whether the difference in task difficulty is indeed the reason in discrepancy between the results of the studies by Satish et al. (2012) and Allen et al. (2015) needs to be examined in the future. However, this discrepancy may be manifestation of more general phenomenon also explaining why in some previous studies no effects of changing indoor climate parameters were seen and in some they were seen.

The present results imply that exposure to pure $\mathrm{CO}_{2}$ concentrations below 5,000 ppm should not raise concerns regarding discomfort or risks for health. These results are valid for healthy young students and short exposures. Consequently, any discomfort and acute health symptoms due to insufficient ventilation should probably not be attributed to the presence of $\mathrm{CO}_{2}$, but to the presence of other pollutants originating indoors or outdoors, and/or to the products of chemical reactions and transformations; symptoms can also have a psychological origin (Brauer et al., 2006). Zhang et al. (2016a,b) showed directly that the effects should be attributed to other pollutants than $\mathrm{CO}_{2}$. They examined the effects of bioeffluents when ventilation rate was restricted to keep the metabolically-generated $\mathrm{CO}_{2}$ at $1,000 \mathrm{ppm}$ or 3,000 ppm. Contrary to the results obtained in the same experiment during exposure to pure $\mathrm{CO}_{2}$ at the same concentrations, exposure to bioeffluents significantly decreased the perceived air quality of visitors (when $\mathrm{CO}_{2}$ was at 1,000 and 3,000 ppm), increased the intensity of reported headache, sleepiness, fatigue and difficulty in thinking clearly, and reduced speed of addition, the response time in a redirection task and the number of correct links made in the cueutilisation test (when $\mathrm{CO}_{2}$ was at 3,000 ppm). They concluded that moderate concentrations 
of bioeffluents, but not pure $\mathrm{CO}_{2}$, would result in deleterious effects on occupants during typical indoor exposure. Sarbu and Pacurar (2015) found that the performance of two cognitive tests continued to improve linearly when bioeffluents levels reduced as indicated by a decrease of $\mathrm{CO}_{2}$ level from 1,000 to 500 ppm. Ramalho et al. (2015) confirmed that even with low $\mathrm{CO}_{2}$ levels (i.e. high ventilation rate), the reduction of other pollutants remains necessary to avoid the exceedance of health guideline values and to achieve a satisfactory indoor air quality.

The exposure duration in the climate chamber was 2.5 hours. This was shorter than the exposure of 4.25 hours in the study by Zhang et al. $(2016 a, b)$ and 8 hours by Allen et al. (2015), but was the same as in the study by Satish et al. (2012). Two and a half hours can also be considered as a typical duration of a long lecture or a period of an uninterrupted work segment. The total dose of $\mathrm{CO}_{2}$ received by subjects in this study was $5,000 \mathrm{ppm} \times 2.5 \mathrm{~h}=$ $12,500 \mathrm{ppm} \cdot \mathrm{h}$, which was close to the dose subjects received in the study by Zhang et al. (2016a,b), in which the dose was 3,000 ppm $\times 4 \mathrm{~h}=12,000 \mathrm{ppm} \cdot \mathrm{h}$. However, in the present experiment the initial level of $\mathrm{CO}_{2}$ was about 1.7 times higher. Whether present results can be extrapolated to longer exposure durations is unknown. It is also uncertain whether longer exposures would evoke acute health symptoms. Future work should further examine whether the prevalence of symptoms is dependent on the level of initial exposure, dose level, exposure duration or all these factors.

The background noise level in the chamber was $48 \mathrm{~dB}(\mathrm{~A})$. It was slightly on a higher side and was caused by the running ventilation fans. However, the subjects did not complain that the chamber was too noisy (data not shown). They did not complain of reduced well-being either (see Fig. 3 in the Results section). In previous studies noise level up to $48 \mathrm{~dB}(\mathrm{~A})$ did not obscure the effects of reduced air quality on performance of tasks resembling office work (Wargocki et al., 1999, 2000; Zhang et al., 2016a,b). It is therefore unlikely that moderately 
elevated acoustic levels in the present experiments could disturb the results. Future studies should nevertheless reduce to minimum the influence of factors such as background noise level that could potentially disturb the results.

One limitation of the present experiment is that only young and healthy college-age students participated and this is not a baseline population. A recent study by Tham and Fadeyi (2015) shows that atopic subjects were less sensitive to poor air quality than non-atopic subjects. Their study found also that, when exposed to poor air quality, atopic participants reported generally higher intensity of physiological symptoms and performed less well in the concentration test. Whether exposure to elevated $\mathrm{CO}_{2}$ would cause negative effects on other populations, e.g. atopic individuals, elderly and infants, needs to be studied in the future experiments.

\section{Conclusions}

- Compared to $\mathrm{CO}_{2}$ at 500 ppm, 2.5-hour exposures to artificially raised $\mathrm{CO}_{2}$ close to 5,000 ppm did not cause any significant changes in perceived air quality, acute health symptoms or the performance of tasks resembling typical office work.

- Compared to $\mathrm{CO}_{2}$ at 500 ppm, 2.5-hour exposures to artificially raised $\mathrm{CO}_{2}$ at 5,000 ppm increased $\mathrm{ETCO}_{2}$ slightly more. No other significant changes were seen in the measured physiological responses, which included blood pressure, respiration rate and stress biomarkers.

- Further research is needed to investigate the effects of high $\mathrm{CO}_{2}$ exposure on cognitive performance using a variety of tasks with different levels of difficulty, while concurrently measuring stress level. 


\section{Acknowledgements}

This work was supported by Bjarne Saxhof Foundation, Key Program of National Natural Science Foundation of China (51238005), and COWI Foundation (HHT/A127.02/knl). We thank our DTU colleague Professor David Wyon for providing extensive comments on the manuscript.

\section{References:}

ACGIH (2011) Documentation of the Threshold Limit Values and Biological Exposure Indices, Cincinnati $\mathrm{OH}$, American Conference of Governmental Industrial Hygienists.

Albrechtsen, O. (1988) Twin climatic chambers to study sick and healthy buildings. In: Proceedings of Healthy Buildings '88, Vol 3, pp. 25-30.

Allen, J.G., Macnaughton, P., Satish, U., Santanam, S., Vallarino, J. and Spengler, J.D. (2015) Associations of cognitive function scores with carbon dioxide, ventilation, and volatile organic compound exposures in office workers: a controlled exposure study of green and conventional office environments, Environ. Health Persp.

Apte, M.G., Fisk, W.J. and Daisey, J.M. (2000) Associations between indoor $\mathrm{CO}_{2}$ concentrations and sick building syndrome symptoms in U.S. office buildings: an analysis of the 1994-1996 BASE study data, Indoor Air, 10, 246-257.

Bakó-Biró, Z.S., Kochhar, N., Clements-Croome, D.J., Awbi, H.B. and Williams, M. (2008) Ventilation rates in schools and pupil's performance using computerized assessment tests, Build. Environ., 43, 362-367.

Bailey, J.E., Argyropoulos, S.V., Kendrick, A.H. and Nutt, D.J. (2005) Behavioral and cardiovascular effects of $7.5 \% \mathrm{CO}_{2}$ in human volunteers, Depress. Anxiety, 21, 18-25.

Brauer, C., Kolstad, H., Ørbæk, P., and Mikkelsen, S. (2006) No consistent risk factor pattern for symptoms related to the sick building syndrome: a prospective population based study. Int. Arch. Occ. Env., 79, 453-464.

Breuer, K. and Satish, U. (2003) Emergency management simulations: an approach to the assessment of decision-making processes in complex dynamic crisis environments, From modeling to managing security: A system dynamics approach, Norway, In: N. A. Press, 145156.

Canadian Center for Occupational and Health and Safety (CCOHS) (2005) Health Effects of Carbon Dioxide Gas. Summary of Occupational Risks, Effects, and Standards for $\mathrm{CO}_{2}$. www.ccohs.ca/oshanswers/chemicals/chem_profiles/carbon_dioxide.html

Case, E. M., and Haldane, J. B. S. (1941) Human physiology under high pressure: I. Effects of Nitrogen, Carbon Dioxide, and Cold. J. Hyg-cambridge, 41, 225-249.

Coley, D.A., Greeves, R. and Saxby, B.K. (2004) The effect of low ventilation rates on the cognitive function of a primary school class, Int. J. of Vent, 6, 107-112.

Erdmann, C.A., Steiner, K.C. and Apte, M.G. (2002) Indoor Carbon Dioxide Concentrations and Sick Building Syndrome Symptoms in the Base Study Revisted: Analyses of the 100 Building Dataset, Lawrence Berkeley National Laboratory.

Consolazio, W. V., Fisher, M. B., Pace, N., Pecora, L. J., Pitts, G. C., and Behnke, A. R. (1947) Effects on man of high concentrations of carbon dioxide in relation to various oxygen pressures during exposures as long as 72 hours. Am. J. Physiol.-Legacy Cont., 151, 479-503. Fang, L., Clausen, G. and Fanger, P.O. (1998a) Impact of temperature and humidity on 
perception of indoor air quality during immediate and longer whole-body exposures, Indoor Air, 8, 276-284.

Fang, L., Clausen, G. and Fanger, P.O. (1998b) Impact of temperature and humidity on the perception of indoor air quality, Indoor Air, 8, 80-90.

Faul, F., Erdfelder, E., Lang, A.G., and Buchner, A. (2007) G*Power 3: A flexible statistical power analysis program for the social, behavioral, and biomedical sciences. Behav. Res. Meth., 39, 175-191.

Guillerm, R. and Radziszewski, E. (1978) Effects on man of 30-day exposure to a PICO2 of 14 torr (2\%): application to exposure limits. Undersea Biomed. Res., 6, S91-114.

Haverinen-Shaughnessy, U., Moschandreas, D.J. and Shaughnessy, R.J. (2011) Association between substandard classroom ventilation rates and students' academic achievement, Indoor Air, 21, 121-131.

Henning, R. A., Sauter, S. L., Reddan, W. G., and Lanphier, E. H. (1985) Behavioral impairment with normobaric, hyperoxic $6 \% \mathrm{CO}_{2}$. Undersea Biomed. Res., 12.

Kajtár, L. and Herczeg, L. (2012) Influence of carbon-dioxide concentration on human wellbeing and intensity of mental work, Q. J. Hungari. Meteor. Serv., 116, 145-169.

Kjærgaard, S., Hauschildt, P., Pejtersen, J., and Mølhave, L. (1999) Human exposure to emissions from building materials. In: Proceedings of the 8th International Conference on Indoor Air Quality and Climate, pp. 507-512.

Lan, L. and Lian, Z. (2010) Application of statistical power analysis - How to determine the right sample size in human health, comfort and productivity research, Build. Environ., 45, 1202-1213.

Lan, L., Wargocki, P., Wyon, D. P. and Lian, Z. (2011) Effects of thermal discomfort in an office on perceived air quality, SBS symptoms, physiological responses, and human performance. Indoor Air, 21, 376-390.

Law, J., Watkins, S. and Alexander, D. (2010) In flight carbon dioxide exposures and related symptoms: association, susceptibility, and operational implications, Houston, TX, NASA Johnson Space Center.

Levenshtein, V.I. (1966) Binary codes capable of correcting deletions, insertions, and reversals, Sov. Phys. Dokl., 10, 707-710.

Liu, W.W., and Wargocki, P. (2015) The effect of high air temperature and $\mathrm{CO}_{2}$ concentration on human subjective responses, In: Proceedings of Healthy Buildings Europe 2015, Eindhoven, Netherland, 2015.

Liu, W.W., Zhong, W.D. and Wargocki, P. (2016) Perceived air quality, acute health symptoms and performance at high temperature and high carbon dioxide concentrations, Environ. Health Persp. (under review).

Maresh, C.M., Armstrong, L.E., Kavouras, S.A., Allen, G.J., Casa, D.J., Whittlesey, M. and Lagasse, K.E. (1997) Physiological and psychological effects associated with high carbon dioxide levels in healthy men, Aviat. Space Envir. Md., 68, 41-45.

Mendell, M.J., Eliseeva, E.A., Davies, M.M., Spears, M., Lobscheid, A., Fisk, W.J. and Apte, M.G. (2013) Association of classroom ventilation with reduced illness absence: a prospective study in California elementary schools, Indoor Air, 23, 515-528.

Milton, D.K., Glencross, P.M. and Walters, M.D. (2000) Risk of sick leave associated with outdoor air supply rate, humidification, and occupant complaints, Indoor Air, 10, 212-221.

Myhrvold, A. and Olesen, E. (1997) Pupils health and performance due to renovation of schools, In: Proceedings of Healthy Buildings/IAQ '97, Vol 1, pp. 81-86.

Myhrvold, A.N., Olsen, E. and Lauridsen,Ø. (1996) Indoor environment in schools - pupils health and performance in regard to $\mathrm{CO}_{2}$ concentrations. In: Proceedings of Indoor Air '96, Vol 1, pp. 369-374. 
Partington, J.E. (1949) Detailed instructions for administering Partington's pathways test, Psychol. Serv. Cent. J., 1, 46-48.

Partington, J.E. and Leiter, R.G. (1949) Partington's pathways test, Psychol. Serv. Cent. J., 1, 11-20.

Pejtersen, J., Brohus, H., Hyldgaard, C. E., Nielsen, J. B., Valbjørn, O., Hauschildt, P., Kjærgaard, S. K., and Wolkoff, P. (2001) Effect of renovating an office building on occupants' comfort and health. Indoor Air, 11, 10-25.

Pettenkofer, M.V. (1858) Über den Luftwechsel in Wohngebäuden, München, Cotta'schenbuchhandlung.

Ramalho, O., Wyart, G., Mandin, C., Blondeau, P., Cabanes, P.A., Leclerc, N., Mullot, J., Boulanger, G. and Redaelli, M. (2015) Association of carbon dioxide with indoor air pollutants and exceedance of health guideline values, Build. Environ., http://dx.doi.org/10.1016/j.buildenv.2015.03.018.

Sarbu, I. and Pacurar, C. (2015) Experimental and numerical research to assess indoor environment quality and schoolwork performance in university classrooms. Build. Environ., 93, 141-154.

Satish, U., Mendell, M.J., Shekhar, K., Hotchi, T., Sullivan, D., Streufert, S. and Fisk, W.J. (2012) Is $\mathrm{CO}_{2}$ an indoor pollutant? Direct effects of low-to-moderate $\mathrm{CO}_{2}$ concentrations on human decision-making performance, Environ. Health Persp., 120, 1671-1705.

Satish, U., Streufert, S., Dewan, M. and Voort, S.V. (2004) Improvements in simulated real world relevant performance for patients with seasonal allergic rhinitis: impact of desloratadine, Allergy, 59, 415-420.

Sayers, J.A., Smith, R.E.A., Holland, R.L. and Keatinge, W.R. (1987) Effects of carbon dioxide on mental performance, J. Appl. Physiol., 63, 25-30.

Schaefer, K. E. (1979) Physiological stresses related to hypercapnia during patrols on submarines. Undersea Biomed. Res., 6, S15-47.

Schaefer, K.E., Hastings, B.J., Carey, C.R. and Nichols, G. (1963) Respiratory acclimatization to carbon dioxide, J. Appl. Physiol., 18, 1071-1078.

Sechzer, P.H., Egbert, L.D., Linde, H.W., Cooper, D.Y., Dripps, R.D. and Price, H.L. (1960) Effect of $\mathrm{CO}_{2}$ inhalation on arterial pressure, ECG and plasma catecholamines and 17-OH corticosteroids in normal man, J. Appl. Physiol., 15, 454-458.

Seppänen, O.A., Fisk, W.J. and Mendell, M.J. (1999) Association of ventilation rates and $\mathrm{CO}_{2}$ concentrations with health and other responses in commercial and institutional buildings, Indoor Air, 9, 226-252.

Sheehy, J. B., Kamon, E., and Kiser, D. (1982) Effects of carbon dioxide inhalation on psychomotor and mental performance during exercise and recovery. Hum. Factors: J. Hum. Factors Ergon. Society, 24, 581-588.

Streufert, S., Pogash, R. and Piasecki, M. (1988) Simulation-based assessment of managerial competence: reliability and validity, Pers. Psychol., 41, 537-557.

Tham, K. W. and Fadeyi, M. O. (2015) Towards whom should indoor environmental quality control be sympathetic-Asthmatics or non-asthmatics? Build. Environ., 88, 55-64.

Woods, S.W., Charney, D.S., Goodman, W.K. and Heninger, G.R. (1988) Carbon dioxideinduced anxiety: Behavioral, physiologic, and biochemical effects of carbon dioxide in patients with panic disorders and healthy subjects, Arch. Gen. Psychiat., 45, 43-52.

Wargocki, P. (2004) Sensory pollution sources in buildings. Indoor Air, 14, 82-91.

Wargocki, P. and Wyon, D. P. (2013) Providing better thermal and air quality conditions in school classrooms would be cost-effective. Build. Environ., 59, 581-589.

Wargocki P., Wyon D.P., Baik Y.K., Clausen G. and Fanger P.O. (1999) Perceived air quality, sick building syndrome (SBS) symptoms and productivity in an office with two different pollution loads, Indoor Air, 9, 165-179. 
Wargocki P., Wyon D.P., Sundell J., Clausen G. and Fanger P. (2000) The effects of outdoor air supply rate in an office on perceived air quality, sick building syndrome (SBS) symptoms and productivity, Indoor Air, 10, 222-236.

Yerkes, R.M. and J.D. Dodson (1908) The relation of strength of stimulus to rapidity of habitformation. J. Comp. Neurol. Psychol, 18, 459-482.

Zhang, X.J., Wargocki, P. and Lian, Z.W. (2016a) Physiological responses during exposure to carbon dioxide and bioeffluents at levels typically occurring indoors, Indoor Air, DOI: 10.1111/ina.12286.

Zhang, X.J., Wargocki, P., Lian, Z.W. and Thyregod, C. (2016b) Effects of exposure to carbon dioxide and bioeffluents on perceived air quality, self-assessed acute health symptoms and cognitive performance, Indoor Air, DOI: 10.1111/ina.12284. 


\section{Highlights}

- 2.5-hour exposure to $\mathrm{CO}_{2}$ up to 5,000 ppm did not decrease perceived air quality

- 2.5-hour exposure to $\mathrm{CO}_{2}$ up to 5,000 ppm did not evoke acute health symptoms

- The examined $\mathrm{CO}_{2}$ exposures did not affect performance of some cognitive tasks

- Discomfort and building related symptoms should not be attributed to $\mathrm{CO}_{2}$ 